\title{
A Study on the Relationship Between Sleep Time and HbA1c in Korean Adult Female
}

\author{
Ji-Yeon Choi ${ }^{1}$ and Ji-Eun Shin $^{2 *}$ \\ ${ }^{1}$ Department of Nursing, Gimcheon University, 214, Daehak-ro, Gimcheon City, \\ Gyungbuk, 39528, Korea \\ ${ }^{2}$ (Corresponding author) Information \& Statistics, Chungnam National University, \\ 99, Daehak-ro, Yuseong-gu, Daejeon, 34134, Korea \\ 1'cjy1218@gimcheon.ac.kr, ${ }^{2} 598977 @$ daum.net
}

\begin{abstract}
The purpose of this study was to determine the relationship between glycated hemoglobin and sleep time in each age group of Korean females. The candidates of study subjects were 16, 277 females from the 7th National Health and Nutrition Survey (2016-2017), and raw data from 6,266 females were included in the final analysis. For the analysis, complex sample chi-square test, General Linear Model (GLM), and complex sample logistic model were performed. Results: The sleep time showed a statistically significant difference in the adolescent and middle-aged groups, however, this significance survived only in the middleaged group after applying covariates, indicating that longer sleep time is associated with a higher risk of diabetes mellitus. It is expected that, based on these results, the monitoring of sleep time and glycated hemoglobin is used in screening diabetes mellitus complications and other various health problems.
\end{abstract}

Keywords: Sleep, Diabetes mellitus, Glycated hemoglobins, Adult, National health and nutrition survey

\section{Introduction}

\subsection{Background}

The development of industrial technology and civilization in complex modern societies has greatly influenced the sleep patterns of humans, resulting in an increased prevalence of diabetes [1]. Even though the American National Sleep Foundation, recently, recommended the appropriate sleeping time of adults as 7-9 hours a day [2], sleep deprivation is a common condition in modern society and an issue in the field of public health [3]. In the Korean population, in particular, sleeping time is short as evidenced by the fact that sleeping time of fewer than 6.5 hours is $50 \%$ of the general population. The ratio of respondents who did not feel sleeping problems for the past month, in addition, was only $14 \%$ and the quality of sleep was also poor [4]. The prevalence of diabetes, accordingly, is increasing steadily.

Article history:

Received (March 27, 2019), Review Result (April 28, 2019), Accepted (May 29, 2019) 
The number of patients with diabetes has increased from about 320 million in 2014 to 425 million in 2017 worldwide, and over four million people died in 2017 due to diabetes and associated complications. It is expected that, based on this rapid trend, patients with diabetes will reach 693 million in 2045 and become serious social problems.

This trend is also observed in Korea; according to the report by Korean Diabetes Association in 2018, the prevalence of diabetes mellitus was $15 . \%$ in men and $13 \%$ in women over 30 years old and this disease was the fifth leading cause of death.

It was reported that sleep deprivation and other sleep problems are associated with various cardio-cerebrovascular diseases such as hypertension and diabetes and obesity. A small number of previous studies, in addition, have suggested that sleeping time is associated with diabetes and that sleep affects diabetes mellitus, which accounts for the majority of deaths [5].

In Korean studies, personal factors such as sex and age have been reported to be associated with sleep time and glycated hemoglobin. Kim showed that sleep and diabetes are not related, and need further research. For the studies in another country, Hiromi Nakajima who observed a change in insulin sensitivity of 20 American male subjects while limiting their sleep time to under five hours a day reported that insulin sensitivity decreased. Despite these results of previous studies, there have been few studies that have analyzed the relationship between sleep time and glycated hemoglobin. The purpose of this study was, therefore, to provide basic data for the prevention and management of diabetes mellitus by investigating the influencing factors of glycated hemoglobin in Korean adult females from adolescents (early adult) to the elderly based on the Life Cycle Theory of Errikson, a German psychologist. For this purpose, the relationship between sleep time and glycated hemoglobin of each age group in three groups, normal group (NG), impaired fasting glucose group (IFGG), and diabetic group (DG), based on data from the 7th National Health and Nutrition Survey (2016-2017).

\subsection{Purpose}

The purpose of this study was to determine the effect of sleep on glycated hemoglobin and to provide basic data for the prevention and management of diabetes mellitus by investigating the influencing factors of the relationship between sleep time and glycated hemoglobin in Korean adult females.

The specific purposes are as follows:

- To investigate the diabetes mellitus distribution in each age group.

- To analyze the difference in glycated hemoglobin and diabetes mellitus according to the general and health-related characteristics of each age group.

- To determine whether sleep time has an effect on glycated hemoglobin and diabetes mellitus in each age group.

\subsection{Definition}

(1) Sleep

Sleep is for restoring the motivation of the activity by recovering from physical and mental fatigue and the required sleep time depends on the age and securing such time is important in promoting the treatment of disease [6].

(2) Diabetes mellitus

The criteria for diagnosing diabetes mellitus include glycated hemoglobin $\geq 6.5 \%, 8$ hours fasting plasma glucose $\geq 126 / \mathrm{dL}$, plasma glucose two hours after oral glucose tolerance test $\geq$ $200 \mathrm{mg} / \mathrm{dL}$, and typical symptoms of diabetes (polydipsia, polyuria), among which, most 
widely used one in diagnosing and management of diabetes mellitus and predicting complications is glycated hemoglobin.

(3) Glycated Hemoglobin

The glycation in glycated hemoglobin (Hemoglobin A1c, HbA1c) means the nonenzymatic addition of sugar residue into the amino group of proteins. and the test is available regardless of fasting. This value shows a comprehensive 8-12-week glucose status, thus, has been used as an important indicator in long-term blood glucose control.

\section{Method}

\subsection{Design}

This second analysis study was to investigate the relationship between sleep and glynated hemoglobin in adults and acquired permission to use raw data from the 7th National Health and Nutrition Survey (2016-2017) hosted by Korean Centers for Disease Control and Prevention.

\subsection{Subjects and analysis}

The candidates of study subjects were 6,599 females over 12 years old from 16,277 participants of the 7th National Health and Nutrition Survey (2016-2017). This study performed complex sample analysis by applying new integrated weights generated from integrating strata for variation prediction (kstrata), survey district (psu), and 7th wave (20162017) data.

The analysis for each age group of adolescents, adults, middle-aged, and elderly. The chisquare test was performed and a general linear model was applied to investigate the general characteristics and distribution of each group (NG, IFGG, and DG) by investigating the relationship between socio-demographic variables and health-related ones. The risk of diabetes mellitus was determined by applying a complex sample logistic model adjusted by sociodemographic and health-related variables.

\subsection{Results}

\subsubsection{Glycated hemoglobin and diabetes mellitus profile by age groups}

The proportion of subjects diagnosed with diabetes mellitus was $0.5 \%$ in adolescents, $0.8 \%$ in adults, $9.2 \%$ in middle-aged, and $6.1 \%$ in the elderly showing an increasing trend by age.

Table 1. Diabetic mellitus profile by age groups

\begin{tabular}{|c|c|c|c|c|}
\hline Groups: Age & NG & IFGG & DG & Total \\
\hline Adolescent (Early adult): 12-19 & $444(93.9)$ & $30(5.6)$ & $1(0.5)$ & $475(100)$ \\
\hline Adult: 20-39 & $1446(91.3)$ & $149(7.9)$ & $16(0.8)$ & $1611(100)$ \\
\hline Middle-aged: 40-59 & $2094(69.9)$ & $655(20.9)$ & $278(9.2)$ & $3027(100)$ \\
\hline Elderly: over 60 & $685(46.1)$ & $419(27.8)$ & $382(26.1)$ & $1486(100)$ \\
\hline Total & $4669(74.5)$ & $1253(16.9)$ & $677(8.7)$ & $6599(100)$ \\
\hline \multicolumn{2}{|r|}{ Rau-Scott $\mathrm{x}^{2}=680.284, \mathrm{df}=6, \mathrm{p}<.0001$} \\
\hline
\end{tabular}


The proportions of impaired fasting glucose were also 5.6\%, 7.9\%, 20.9\%, and $27.8 \%$, respectively, increasing also by age.

Table 2. Socio-demographic and health-related factors by diabetes Miletus groups

\begin{tabular}{|c|c|c|c|c|c|c|c|c|c|}
\hline & & \multicolumn{2}{|c|}{ Adolescent } & \multicolumn{2}{|r|}{ Adult } & \multicolumn{2}{|c|}{ Middle-aged } & \multicolumn{2}{|r|}{ Elderly } \\
\hline & & \begin{tabular}{|l|} 
Odds \\
ratio
\end{tabular} & (95\% C.I.) & $\begin{array}{l}\text { Odds } \\
\text { ratio }\end{array}$ & (95\% C.I.) & $\begin{array}{l}\text { Odds } \\
\text { ratio }\end{array}$ & (95\% C.I.) & $\begin{array}{l}\text { Odds } \\
\text { ratio }\end{array}$ & (95\% C.I.) \\
\hline \multicolumn{2}{|c|}{ Age } & 1.019 & $\begin{array}{l}(0.727- \\
1.428)\end{array}$ & 1.072 & $\begin{array}{l}(1.013- \\
1.135)\end{array}$ & 0.979 & $(0.96-0.999)$ & 0.966 & $\begin{array}{l}(0.931- \\
1.002)\end{array}$ \\
\hline \multirow{4}{*}{$\begin{array}{l}\text { Education } \\
\text { Level }\end{array}$} & Elementary & & & 1 & & 1 & & 1 & \\
\hline & Middle & & & 0.056 & $\begin{array}{l}(0.006- \\
0.559)\end{array}$ & 1.45 & $\begin{array}{l}(0.941- \\
2.235)\end{array}$ & 1 & $\begin{array}{l}(0.514- \\
1.948)\end{array}$ \\
\hline & High & & & 0.087 & $\begin{array}{c}(0.009- \\
0.844)\end{array}$ & 1.037 & $\begin{array}{c}(0.695- \\
1.548)\end{array}$ & 1.366 & $\begin{array}{c}(0.798- \\
2.338)\end{array}$ \\
\hline & Collage & & & 0.076 & $\begin{array}{l}(0.005- \\
1.095)\end{array}$ & 1.156 & $\begin{array}{l}(0.735- \\
1.819)\end{array}$ & 0.789 & $\begin{array}{l}(0.506- \\
1.232)\end{array}$ \\
\hline \multirow{2}{*}{$\begin{array}{c}\text { Marital } \\
\text { Status }\end{array}$} & Yae & & & 1 & & 1 & & 1 & \\
\hline & No & & & 0.897 & $\begin{array}{c}(0.459- \\
1.751)\end{array}$ & 1.788 & $\begin{array}{c}(0.852- \\
3.753)\end{array}$ & 1.269 & $(0.26-6.192)$ \\
\hline \multicolumn{2}{|c|}{ Waist Circumference } & 1.106 & $\begin{array}{c}(1.044- \\
1.172) \\
\end{array}$ & 1.077 & $(1.05-1.104)$ & 0.931 & $\begin{array}{c}(0.919- \\
0.944)\end{array}$ & 0.949 & $\begin{array}{c}(0.929- \\
0.969)\end{array}$ \\
\hline \multirow[t]{4}{*}{ Smoking } & No & & & 1 & & 1 & & 1 & \\
\hline & Every day & & & 1.258 & $\begin{array}{l}(0.563- \\
2.813)\end{array}$ & 0.715 & $(0.41-1.247)$ & 1.005 & $\begin{array}{l}(0.394- \\
2.562) \\
\end{array}$ \\
\hline & Sometime & & & 1.244 & $\begin{array}{c}(0.324- \\
4.776)\end{array}$ & 0.888 & $\begin{array}{c}(0.351- \\
2.249) \\
\end{array}$ & 0.209 & $\begin{array}{c}(0.011- \\
3.912)\end{array}$ \\
\hline & Exsmoker & & & 0.541 & $\begin{array}{l}(0.179- \\
1.632)\end{array}$ & 0.945 & $(0.42-2.124)$ & 0.494 & $\begin{array}{l}(0.129- \\
1.893)\end{array}$ \\
\hline \multirow[t]{4}{*}{ Income } & No & & & 1 & & 1 & & 1 & \\
\hline & Medium & 1.121 & $\begin{array}{l}(0.185- \\
6.797)\end{array}$ & 1.25 & $\begin{array}{l}(0.441- \\
3.545)\end{array}$ & 1.434 & $\begin{array}{l}(0.954- \\
2.156)\end{array}$ & 1.185 & $\begin{array}{l}(0.633- \\
2.219)\end{array}$ \\
\hline & Slander & 0.808 & $\begin{array}{c}(0.118- \\
5.546)\end{array}$ & 1.379 & $\begin{array}{c}(0.505- \\
3.764)\end{array}$ & 1.448 & $(0.976-2.15)$ & 0.721 & $(0.437-1.19)$ \\
\hline & Prize & 1.659 & $\begin{array}{l}(0.269- \\
10.212)\end{array}$ & 1.145 & $(0.403-3.25)$ & 1.622 & $\begin{array}{l}(1.067- \\
2.465)\end{array}$ & 1.19 & $\begin{array}{l}(0.748- \\
1.894)\end{array}$ \\
\hline \multirow[t]{6}{*}{ Drinking } & No & & & 1 & & 1 & & 1 & \\
\hline & $<1 /$ month & & & 0.892 & $\begin{array}{l}(0.244- \\
3.264) \\
\end{array}$ & 1.452 & $\begin{array}{c}(0.648- \\
3.254)\end{array}$ & 0.778 & $\begin{array}{l}(0.197- \\
3.071)\end{array}$ \\
\hline & $1 /$ month & & & 1.273 & $\begin{array}{l}(0.561- \\
2.889)\end{array}$ & 1.367 & $\begin{array}{l}(0.898- \\
2.081)\end{array}$ & 0.781 & $\begin{array}{l}(0.263- \\
2.319)\end{array}$ \\
\hline & $2 \sim 3 /$ month & & & 1.487 & $\begin{array}{l}(0.736- \\
3.005)\end{array}$ & 1.192 & $\begin{array}{c}(0.846- \\
1.678)\end{array}$ & 0.873 & $(0.473-1.61)$ \\
\hline & 2 3/week & & & 1.192 & $\begin{array}{l}(0.498- \\
2.852)\end{array}$ & 1.086 & $\begin{array}{c}(0.713- \\
1.654)\end{array}$ & 1.081 & $\begin{array}{c}(0.596- \\
1.959)\end{array}$ \\
\hline & $>4 /$ week & & & 1.159 & $\begin{array}{l}(0.572- \\
2.348) \\
\end{array}$ & 1.218 & $\begin{array}{l}(0.882- \\
1.682) \\
\end{array}$ & 1.043 & $\begin{array}{c}(0.676- \\
1.609) \\
\end{array}$ \\
\hline \multicolumn{2}{|c|}{ Stress } & 1.235 & $(0.5-3.047)$ & 1.273 & $\begin{array}{c}(0.897- \\
1.807) \\
\end{array}$ & 1.051 & $\begin{array}{l}(0.878- \\
1.258) \\
\end{array}$ & 1.038 & $\begin{array}{l}(0.831- \\
1.298) \\
\end{array}$ \\
\hline \multicolumn{2}{|c|}{$\begin{array}{l}\text { Physical Activity } \\
\text { (minute/day) }\end{array}$} & 0.999 & $\begin{array}{l}(0.997- \\
1.002) \\
\end{array}$ & 1 & $(1-1.001)$ & 1 & $(0.999-1)$ & 1 & $(1-1.001)$ \\
\hline \multirow{2}{*}{$\begin{array}{l}\text { Family } \\
\text { History }\end{array}$} & No & 1 & & 1 & & 1 & & 1 & \\
\hline & Yes & 3.018 & $\begin{array}{l}(0.464- \\
19.62)\end{array}$ & 1.806 & $\begin{array}{l}(1.074- \\
3.038)\end{array}$ & 0.542 & $(0.432-0.68)$ & 0.374 & $\begin{array}{c}(0.247- \\
0.566)\end{array}$ \\
\hline Hypotension & No & & & & & 1 & & 1 & \\
\hline
\end{tabular}




\begin{tabular}{|c|c|c|c|c|c|c|c|c|c|}
\hline & Yes & & & & & 0.567 & $\begin{array}{c}(0.409- \\
0.785)\end{array}$ & 0.579 & $\begin{array}{c}(0.395- \\
0.849)\end{array}$ \\
\hline Sleep time & $<6 \mathrm{hr}$ & & & & & & & & \\
\hline & $<7 \mathrm{hr}$ & 5.318 & $\begin{array}{c}(0.945- \\
29.921)\end{array}$ & 1.14 & $\begin{array}{c}(0.491- \\
2.648)\end{array}$ & 1.562 & $\begin{array}{c}(1.121- \\
2.177)\end{array}$ & 0.788 & $\begin{array}{c}(0.505- \\
1.228)\end{array}$ \\
\hline & $<8 \mathrm{hr}$ & 0.936 & $(0.11-7.99)$ & 1.172 & $\begin{array}{c}(0.519- \\
2.648)\end{array}$ & 1.512 & $\begin{array}{c}(1.091- \\
2.094)\end{array}$ & 1.059 & $(0.66-1.701)$ \\
& $>8 \mathrm{hr}$ & 1.28 & $\begin{array}{c}(0.163- \\
10.068)\end{array}$ & 1.017 & $\begin{array}{c}(0.414- \\
2.499)\end{array}$ & 1.532 & $\begin{array}{c}(1.077- \\
2.179)\end{array}$ & 0.77 & $\begin{array}{c}(0.467- \\
1.268)\end{array}$ \\
\hline & & .153 & & .664 & & .023 & & .544 \\
\hline
\end{tabular}

Covariate: Adolescent - Age, Education level, Income, Stress, Physical Activity, Family history Adult - Age, Education level, Marital status, Smoking, Income, Drinking, Stress, Physical Activity, Family history

Middle-aged, Elderly - Age, Education level, Marital status, Smoking, Income, Alcohol, Stress, Physical Activity, Family history

\subsubsection{Analysis of socio-demographic and health-related factors on glycated hemoglobin and diabetes mellitus groups by age groups}

The results of the analysis to determine whether there is a difference in diabetes mellitus by age groups showed that there was a statistically significant difference in family history $(\mathrm{p}=.008)$ and sleep time $(\mathrm{p}=.030)$ in adolescents and family history $(\mathrm{p}<.001)$, an education level $(\mathrm{p}<.001)$, marital status $(\mathrm{p}<.001)$, and waist circumference $(\mathrm{p}<.001)$ in adults.

The statistically significant differences were also observed in family history $(\mathrm{p}<.001)$, sleep time $(\mathrm{p}=.011)$, an education level $(\mathrm{p}<.001)$, income $(\mathrm{p}<.001)$, drinking $(\mathrm{p}=.006)$, and stress $(\mathrm{p}=.003)$ in middle-aged and in family history $(\mathrm{p}<.001)$, physical activity $(\mathrm{p}=.004)$, and waist circumference $(\mathrm{p}<.001)$.

\subsubsection{The influence of sleep time on glycated hemoglobin and diabetes mellitus}

The influence of sleep time on glycated hemoglobin and diabetes mellitus was analyzed by age group.

The results showed that, in adolescents, the waist circumference $(\mathrm{OR}=1.106)$ was statistically significant and the OR of 7-8 hours of sleep time was low but did not reach statistical significance. In the adult, the waist circumference $(\mathrm{OR}=1.077)$ and family history $(\mathrm{OR}=1.806)$ were statistically significant and the OR of 7-8 hours of sleep time was highest but did not reach statistical significance. In the middle-aged, the highest income level showed the highest OR (1.622) and statistical significance, and waist circumference ( $O R=0.931)$, family history $(\mathrm{OR}=0.542)$, and hypotension $(\mathrm{OR}=0.567)$ showed statistical significance. For the sleep time, 6-7 hours $(\mathrm{OR}=1.562), 7-8$ hours $(\mathrm{OR}=1.512)$, and 8 hours $(\mathrm{OR}=1.532)$ of sleep time showed higher OR compared to less than six hours of sleep time and this difference was statistically significant. In the elderly, the waist circumference $(\mathrm{OR}=0.949)$, family history $(\mathrm{OR}=0.347)$, and hypotension $(\mathrm{OR}=0.579)$ showed statistical significance, and 7-8 hours of sleep time showed higher OR and 6-7 hours and more than 8 hours showed lower OR, however, these differences were not statistically significant.

\section{Conclusion}

The prevalence of diabetes mellitus was highest in the elderly group (26.1\%) and that of impaired fasting glucose was also highest in this group (27.8\%). The influencing factors of glycated hemoglobin and diabetes mellitus were family history in all age groups excluding adolescents, waist circumference in all age groups, lower income, shorter sleep time, hypertension in the middle-aged group, and hypotension in the elderly group. It is 
recommended to develop an intervention program to identify in early time the population vulnerable to glycated hemoglobin and contribute to lower the glycated hemoglobin with agefitted strategies.

\section{References}

[1] Francesco P. Cappuccio, Lanfranco D’Elia, Pasquale Strazzullo, Michelle A. Miller, "Quantity and Quality of Sleep and Incidence of Type 2 Diabetes," Diabetes Care, vol.33, pp.414-420, (2010)

[2] Nation Sleep Foundation, https://sleepfoundation.org

[3] Dinges D.F., "Sleep deprivation and human immune function," Adv Neuroi Mmunol, vol.5, no.2, pp.97-110, (1995) DOI:10.1016/0960-5428(95)00002-J

[4] Woo, J.M., Hyun S.Y., Lee S.H., Kang S.G., Lee J.S., Kim L., et al. "Productivity time lost by sleep disturbance among workers in Korea," Journal of Korean Neuropsychi Atry Association, vol.50, pp.62-68, (2010)

[5] Cappuccio F.P., Cooper D., D’Elia L., Strazzullo P., and Miller M.A., "Sleep duration predicts cardiovascular outcomes: A systematic review and meta-analysis of prospective studies," European Heart Journal, vol.32, pp.1484-1492, (2011) DOI:10.1093/eurheartj/ehr007

[6] Orfeu M. Buxton, Milena Pavlova, Emily W. Reid, Wei Wang, Donald C. Simonson, and Gail K. Adler, "Sleep restriction for 1 week reduces insulin sensitivityin healthy men," Diabetes, vol.59, pp.2126-2133, (2010) DOI: $10.2337 / \mathrm{db} 09-0699$ 